\title{
Analytical Research on Basic Skills of Piano Playing
}

\author{
Zhihua Zhang \\ Faculty of Education \\ Qujing Normal University \\ Qujing, Yunnan, China 655011
}

\begin{abstract}
It is not to excessively enrich tone, increase the volume, nor accelerate pace to play piano successfully. A good piano performance is to express emotion naturally, perform nimbly and control it steadily. It can conquer audiences. Looking back, a good piano performance is performed with skillful application of skills, emotion pouring of heart and delicate music image. Therefore, it can be concluded that the most important is the excellent piano playing skills. Both beginners and learners shall spend a lot of time to practice continuously and repeatedly.
\end{abstract}

Keywords-piano playing; basic skills; texture structure; arm coordination; uniform playing

\section{INTRODUCTION}

Rachmaninoff, the Greatest Pianist and Famous Composer and Conductor in the 20th century, once said: "an excellent pianist shall have clean, fast, clear and flexible basic skills". She/he shall endeavor to exploit "the internal force" of fingers, arms, wrists and other physiological functions. As is known to all, the great pianists in the history never stop learning and practicing basic skills no matter in the initial learning stage or later playing career. It can be seen that the piano playing skills are important. Even piano masters spend a lot of time practicing. We are of no fame, and in the early training stage. We should make great efforts to learn and practice basic skills, and apply them skillfully. It doesn't mean that we shall play quickly, magnificently or flatulently. We should be able to show amazing, delicate and spotless stage effect.

\section{FINGER CONTROL FORCE}

When playing the piano, we should control the strength of the fingers properly. The stress shall be performed strongly, and the unstressed shall be lightly. The strength of stress should like dropping water wearing through a stone, and the strength of the unstressed should like feather blowing face. It is particular about the flexibility and lightness of the fingers. The first point of the flexibility of finger is to touch and leave keys agilely and rapidly. It means players should touch keys rapidly and leave keys fast. Both happen at same time. One rises and one drops, which make perfect sense. It can remove the inertia and numbness of the fingers, and slowness due to softening joints, activate fingers and make them flexible. The second point is to connect key-touching of each finger rapidly, starting from first explosive sound and gradually extending to the connection of three sounds, four sounds and multi-sounds. Players shall drop key of first sound steadily, play each sound accurately and uniformly, and then accelerate the pace. And players shall leave the key of end sound stably. For example, in playing Chopin's Polonaise, players shall perform strongly and vividly in different key-touching of fingers. Thus, in daily practice, players should first use arm force to strike keys and play strong beat and stress. On the basis, play needed sounds, relax fingers' strength appropriately, then quickly play backwards and forwards to keep music continuous. Therefore, it is important to practice fingers separately. Firstly, it can eliminate redundant actions due to joint stiffness mentioned above, and avoid waste time due to slowness and damage of strength caused by insufficient force. Secondly, players shall insist the flexible and independent practice of fingers. At last, players shall enhance the rapid movements of fingers backwards and forwards and improve the overall performance effect.

\section{WRIST DRIVE}

Piano learners know that the stiff wrist and tight arm may produce pure fingertip key-touching and thus cause nail injuries. It also cause over bent fingers and numb arms, which lead to unsatisfactory effect. In fact, it also needs great effort and strength to play the piano well. It is a transfer process, "two shoulders generating power, arms exerting power, wrist driving and fingertip outputting power". Therefore, we can see that the wrist and arm, as the center position of the strength, shall draw high attention, and be practiced a lot, so that they may be resilient and flexible. Thus, players can achieve the perfection.

Therefore, in the specific time, players shall not emphasize the strength and power too much at beginning, but practice with uniform and soft strength. In actual key-touching, do not put fingers on keyboard. Rise forearm to a hovering point, which is the first action. Then keep wrists in a line and steady, control hands to rotate and freely do 180-degree practice or 360-degree practice at different directions and angles clockwise or counterclockwise, up or down, left or right, forward or backward. Or put one hand on keyboard and carry out direction-converting and angle-controlling practice with the other hand according to above process. For example, in playing Liszt' Hero, players shall use wrist and arm, combining with same octave clip at the end, and play with FF strength. In playing Rachmaninoff's Clown, players shall show finger movement perfectly under the drive of arm in distant key skipping. In playing Chopin's Nocturne, players shall exert force with arms and combine with octave chords, and thus play the piano easily. 


\section{BRAIN COORDINATION}

Every successful piano performance is not just simply to step on pedal, drive arms or move fingers back and forth. It is not simple exercise of fingers, arms and waists. Players shall also use their brain to scheme and plan. The playing skills are not all physical performance, which involves in the thinking of brain. In other words, playing skills are media of music connotation and body drive, which belong to the category of intellectual control. It is invisible and abstract. So, in the actual practice, it is necessary to construct the inner world of music image, and accurately grasp the positioning and emotion. Players can feel the fun of music and happiness from music. The improvement of skills can improve the extended creative skills.

\section{UNIFORM PLAYING}

Non-uniform playing is a common problem in arpeggios and scales. Why there is non-uniform or desultory phenomenon in playing? It is because of bad strength control and speed deviation. It shows in disobedient thumb and slow finger crossing. Therefore, the key is in "waist drive" in order to achieve uniform effect and coherent performance. The sounds of black keys involve in diminished seventh chord and other basic skills. If there are many such sounds, players may wrongly understand it in learning. It may lead to unsteady pace and a poor effect. The uniformity, coherence and continuity of performance, just like ballet show, need ceaselessly practice. It is not enough to just rely on performance. Players need practice day by day. Therefore, a good piano performance cannot be obtained in one day. It needs practice and practice day after day and repeatedly strengthen. Aiming at disobedient thumb, players can slow down pace to practice, pay attention to the movement of waists and fingers, and raise the back of hand to the extent that the thumb can cross it. Players shall use the outward fingertip flesh of thumb to touch keys, rather than putting the first joint on keys. Otherwise, it may cause jerky rotation. In selecting practice textures, players can carry out triad (primary chord arpeggio) or quartette (seventh chord arpeggio) rhythm practice, combining with Chopin's $\mathrm{C}$ major and Hanun.

\section{The Combination of Song Music}

With the in-depth study of piano learning, we will find that Czerny's 599 \& 849 Etude, Hanon's Piano Fingers Exercises or Burgmuller's 25 Pieces of Piano Progressive Works have single or several repeated skills representation more or less, such as legato, staccato and concerto skills, returning note and grace note skills, reasonable clause skills, and so on. However, we all know that the ultimate goal of piano performance is to meet the needs of the public, satisfy the public and make them relaxed, physically and mentally happy. The composers wrote different styles of works. And players shall play them with rhythm sensation, accurately and incisively. Players shall be able to speak own words and transfer emotions with piano, which is the ultimate goal of song music. This kind of song music could arouse sympathy of audiences, stimulate their certain feelings, make them recall something and develop audiences' imagination and inspiration.
Music is a form of singing. In the process of touching keys, players can convey their inner feelings, sorrowful or joyful, exciting or calm, strong or tender, presenting a great imaginary space to audiences. It may be a beautiful idyllic land, a tall and noble gentleman image or elegant aesthetic feelings. At the same time, the piano can make a singing sound through the form of music. It waves the movements of fingers, player's intermediate feelings and inner emotions into a system, presenting in overall performance. Therefore, it is not enough to just pursue playing skills. Players should serve the song music.

\section{REASONABLE Clauses}

It is not to play it within one breath. It is very important to play with high-quality musical interpretation, high-grade music transfer and high-content accomplishment. It is particular about reasonable clauses in playing piano which is just like the role of punctuation marks in language. The reasonable setting of punctuations could make article more complete. The reasonable pause in playing piano is like to take a breath in singing. In general, use legato way within a phrase, and raise hand between clauses.

As a single note fails to convey a specific meaning, it is only meaningful in a music phrase or entire music score. That is why players should play, appreciate, learn, think and master phrase to phrase in playing piano, and then finish it on accumulated strength.

In the division of phrases, we can use common and ordinary line of clauses. In playing clauses, players shall stress to play according to rhythm. The start of first sound shall be clear, and the finish of end sound shall be gentle. Players shall emphasize the overall process of music phrase and the expression of music tone.

If encountering clause division problems, players first should consider the music target and effect that the composer pursue, and what kind of music value the composer want to transfer to audiences. Players should not only pay attention to the start and end sound of single phrase, but also keep the musical sense and smooth of overall music, and select appropriate end tone. That is way we said the music playing shall have breath, tone, mood and temperament. In addition, players shall know the profile of composer and the historical background of the works, and make profound analysis, so as to understand the works originally and divide clauses correctly.

\section{BOLD MOVE}

\section{A. Skillful Coordination of the Left Hand and the Right Hand}

According to common sense, it is a very difficult thing to draw a square with one hand and meanwhile draw a circle with the other hand. But in playing the piano, we need one hand to control the main rhythm, and the other hand to coordinate and accompany. It feels that two hands are doing two different things. At start, you will feel that two hands are not coordinated. Learners can practice one hand, and then the hand. Of course, you shall know the general rhythm and tune of the song. It is critical to be slow in practice. Learners shall 
coordinate two hands one phase to one phase, and then will be skilled.

As we all know, in practice, we starts from the practice of left hand. It is because there is a few of chords for left hand. Learners can find repeated chords and practice repeatedly, and then keep in mind. Before practice, learners shall know what you are practicing. It is not wise to practice blindly, for it wastes time and has little effect. On the basis, find melody and musical phrase with right hand. Learners shall know which phrase you are playing, coordinate left and right hands skillfully, and slow down properly. But it does not means that all actions and thinking shall be slowed down. Our eyes and brains shall be quick. We only slow our hand actions, rather than the operation of our thinking. In this way, our brain may have enough time to think, which is particularly important to piano learners.

\section{B. The Close Combination of Tremolo and Large Span}

Fast tremolo is particular about clear and full playing and rhythmic rhythm. As a practice works, Evening Song of the Drunken Fisherman is a difficult song both for learners and players. Its difficulty doesn't lie in skills. The skill that it frequently involves in is the tremolo. But due to the fast playing speed, it is very difficult to play overtone. If learners work hard to practice, this song is not difficult. Most of them can play it. But their performances basically are blurring, mixed and with unclear tremolo or bad large span. Even the overtone at the end is easy to be the combination of discrete tone and overtone.

For the position of large-span sound, learners need to practice repeatedly and keep in mind. Therefore, the sixth sense is particularly important. It helps brain accurately position and fingers find correct keys.

So, it requires learners to be familiar with music score. Once see it, learners should be able to quickly find the position of key in brain, and then directly strike it by the sixth sense unconsciously. Most of the learners are afraid to make mistake in playing. They may worry about the playing effect and wait a long time and then play, which is a disturbance to the memory of muscles. In practice, don't be afraid to make mistakes, and release yourself and play at ease, which is also one playing skill. It is not terrible to play a wrong sound. Repeat more and practice expertly, and then you will be confident and happy in playing. Practice makes perfect. For specific practice, learners could practice Richard Clayderman's A Comm Amour. When first entering the octave large spans in small climax, be bold to play them, find correct position and play fast. Empty your mind. If there is wrong, observe and find the reason, and then adjust and continue practice. You will be successful if you can play each group of octave sounds correctly.

\section{CONCLUSION}

Piano is the king of musical instruments and the overlord of keyboards. Piano art attaches great importance to practice. It requires high performance skills. In the long-term exploration of piano artists, there are many forms of playing skills. The basic skills include uniform control of finger strength, stable waist in fast movements of fingers, the maintenance of waist drive, and descending power to fingertip in a relaxed mood. In addition, fingers, palms, arms and brain shall be coordinated with each other. Players shall pay attention to the excavation of deep feelings, control strength, improve speed and keep playing continuous, coherent and uniform. Only by playing music melody naturally, can the performance move and attract audiences.

\section{REFERENCES}

[1] Guo Dan. How to Improve the Sound Quality of Piano Playing. Northern Music, 2011 (08).

[2] Zhang Yan, Practice of Music Performance and Mood States of Performers. Today's Massmedia, 2010 (09).

[3] Shi Anhong. Analysis of Difficulties and Measures of Octave Skill in Piano Performance. Art Science and Technology, 2013 (06).

[4] Joseph Gath. Piano Playing Skills. Beijing: People's Music Publishing House, 2000.

[5] Chen Xu, Piano Playing Skills. Piano Art, 1997 (3): 16-17. 